\title{
BLOOD SUGAR TIME CURVES
}

By I. M. RABINOWITCH

(From the Department of Metabolism, Montreal General Hospital, Montreal, Canada)

(Received for publication May 21, 1926)

Blood sugar time curves, or what are more generally, but less exactly, termed sugar tolerance curves, are now receiving wide clinical application. As a result of this, various disorders, other than disbetes mellitus, are known to result in, or be associated with, a disturbance in the metabolism of carbohydrates. The response of the individual to glucose ingestion is probably the best of indices of such a disturbance.

It is obvious that the "normal" type of curve must be recognized in order to detect pathological variations. Within the last few years, many different results, obtained in apparently normal individuals, have been recorded. A study of the literature however, shows that in obtaining these results, not only have various procedures been followed as to selection of the amount and type of sugar, and the periodic collection of blood and urine specimens, but the analytical methods for blood sugar estimation have been different. The literature on the subject has become voluminous, and for brevity no attempt at review will be made here, since it would serve no particular purpose in the present discussion.

In spite of the many procedures and different technical methods, a statistical study of all the results would tend to give a fairly approximate idea of what is the response of the normal individual to glucose ingestion. This view is based upon one of the theorems of statistics, namely, that the arithmetical mean of a large series of observed values, is the most probable value of the quantity measured. Such painstaking study has, recently, been made (1). In a comprehensive study, including a statistical analysis of 4000 individual blood sugar determinations in 971 cases, Gray arrived at standards which are generally accepted. The values of the mean and the mode (the most frequent 
results) of the series agreed very closely. The blood sugar time curve is characteristic. The fasting blood sugar is about 0.090 per cent. Following the administration of glucose, the maximum increment is noted within 30 minutes, and the value is below 0.180 per cent, the average peak being 0.140 per cent. The rate of decline is at first rapid, then slower. Within three hours the blood sugar concentration is equal to or below that of the fasting period.

In only 10 of 431 cases was the fasting level above 0.120 per cent. Eight of these were 0.130 per cent. In one case it was 0.150 and in another 0.160 per cent. These data are of particular interest since, in the majority of cases (300 out of 479), the dose of sugar administered by the various workers was that now generally employed, namely, 70 to 100 grams. In the majority of the 300 cases abnormal glycosuresis did not occur. It was, however, found in a sufficient number, namely 129 , to emphasize the difficulty of the interpretation of this phenomenon.

The majority of observers are also in agreement as to the relation between the type of the curve and the dose of sugar given. With as little as 5 grams an appreciable increase was noted. The highest peak with the smallest dose was as great as the average peak with the larger dose. With doses exceeding 25 grams the peak was not affected. Increasing the dose merely prolonged the time necessary for the blood sugar to return to its original fasting level. The difference between the effects of the starches and glucose was too small to determine any special preference.

In spite of these findings, however, one frequently meets with differences of opinion as to what may be regarded as a "normal" curve. There appears to be a fairly general agreement as to the value of the concentration of sugar in the blood in the post absorptive state and the time necessary for the blood sugar to return to the basal level. There is, however, much difference of opinion as to the maximum concentration of blood sugar which may be regarded as normal following glucose ingestion. Blood sugars as high as 0.250 per cent have not been regarded by some observers as pathological, providing they have returned to the normal level in two and a half or three hours. These high values have been attributed to the great differences, in different individuals, of rates of absorption of glucose from the alimentary canal. 
It appears reasonable that this problem would be much simplified if a large series of observations were made by one procedure and one technical method of blood sugar estimation. This has been done and the object of this communication is to record the results of over seven hundred such blood sugar time curves. In each case the following routine was adopted. It is one generally in use, but it is described in detail for the purpose of the present discussion.

No food nor fluids of any kind were allowed after $6 \mathrm{p} . \mathrm{m}$. the evening before the test. In the morning, the patient voided. One hundred grams of ordinary glucose, ${ }^{1}$ dissolved in $250 \mathrm{cc}$. water and flavored with lemon juice were then given, and blood and urine specimens were collected 30, 60, 120 and 180 minutes later. ${ }^{2}$ Benedict's qualitative test was used for detecting sugar in the urine. All blood sugar estimations were made by the Lewis-Benedict method, with slight modifications, but with no alteration in principle. A brief remark with reference to this method may not be out of place.

It is a generally recognized fact, that this procedure yields higher values than the Folin-Wu method. In an investigation such as this, there are, however, other and equally important considerations in the selection of a method. It might be pointed out that much of our knowledge of blood sugar time curves and our ideas of fasting and threshold blood sugar values are the results of work done with picric acid procedures. In fact, though the prevalent method is probably that of Folin and $\mathrm{Wu}$, there is relatively little in the literature on studies of fasting and threshold values made with the use of the Folin and $\mathrm{Wu}$ method, and with "ordinary" glucose. It appears rather illogical to obtain blood sugar time curves by one method, and in the interpretation of results, accept as standards, values obtained by another method, when the methods do not yield identical values.

\footnotetext{
${ }^{3}$ The term ordinary glucose refers to the commercial product. The chemically pure sugar was not used, since it is rarely employed for clinical purposes, and the value of data obtained with it would therefore be limited for comparative purposes.

${ }^{2}$ The collections of accurately timed blood specimens were made possible with the assistance of Drs. F. G. Strean, Harold Eberts, C. N. Ramsay, P. Ward, E. S. Mills, I. Trossman, M. C. Childs, J. B. Ross, F. Hume and B. Alexander, who at different times were house physicians in the Metabolism Service. Grateful acknowledgment is due the Nursing Staff in charge of the various wards who were responsible for the collection of urinary specimens.
} 
The actual glucose content of human blood is still unknown. No better demonstration of this fact can be found than in the continual researches and critical analyses of each other's work by Folin and Benedict. The more recent methods tend to yield lower values. While this important problem is still under investigation it is considered advisable to adhere to one method, the technique of which has been thoroughly mastered. This has been done in this laboratory and during the last six years approximately 30,000 determinations have been made with the method employed in this study. As a result of this experience, we are quite in agreement with Benedict (2) in his assertion that rarely has the clinician been misled in the interpretation of blood sugar results obtained by the picric acid method. We have also frequently noted the fact, mentioned by Benedict, that the rate of return of the blood sugar to the normal level, as found with the picric acid method, paralleled the clinical progress of diabetics more closely than the results with the Folin and Wu method, with which the decline in blood sugar concentration was more rapid.

The method of investigation was, firstly, to accept as a standard curve, for statistical purposes, the average values found by Gray for normal individuals, which are as follows:

a. Post absorptive blood sugar, 0.080 to 0.120 per cent.

$b$. Maximum blood sugar following glucose ingestion not above $0.1 \varepsilon 0$ per cent.

c. Blood sugar at the end of 3 hours $0.0 \varepsilon 0$ to 0.120 per cent.

The clinical picture in each case was correlated with the blood sugar time curve.

Evidence suggesting diminished sugar tolerance was found in 268 out of 713 cases. In 140 out of the 268 cases, the curves showed that hyperglycemia was present at the end of three hours. These are excluded from the present discussion. We are particularly concerned with the 128 remaining curves which showed maximum blood sugar concentrations above 0.180 per cent, and normal blood sugars at the end of 180 minutes. These were divided into two groups according to the clinical pictures with which they were associated as follows:

Group 1. Those conditions known to cause, or to be associated with a disturbance of carbohydrate metabolism.

Group 2. Those in which no reason could be found for the abnormalities in the curves. 
All subjects were hospital cases. In table 1 are recorded in each group the different clinical conditions, and their incidence. It will be noted that in 99 (group 1) out of the 128 cases an incidence of 77.3 per centthe clinical conditions were such as to offer reasonable explanations for the characters of the blood sugar time curves. In only 29 cases

TABLE 1

Subjects with maximum blood sugar concentrations above 0.180 per cent and normal blood sugar after 180 minutes

\begin{tabular}{|c|c|c|c|}
\hline \multicolumn{2}{|l|}{ Group 1} & \multicolumn{2}{|l|}{ Group 2} \\
\hline Clinical diagnosis & $\begin{array}{l}\text { Inci- } \\
\text { dence }\end{array}$ & Clinical diagnosis & $\begin{array}{l}\text { Inci- } \\
\text { dence }\end{array}$ \\
\hline & cases & & cases \\
\hline Glycosuria*................ & 24 & Gastric ulcer.............. & 2 \\
\hline Exophthalmic goiter........... & 21 & Migraine ............. & 2 \\
\hline Toxic adenoma $\ldots \ldots \ldots \ldots \ldots \ldots$ & 4 & Chronic tonsillitis . . . . . . . . & 1 \\
\hline Rheumatoid arthritis.......... & 8 & 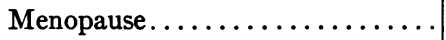 & 4 \\
\hline Chronic pancreatitis............ & 3 & 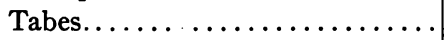 & 1 \\
\hline Chronic cholecystitis . ......... & 5 & Chronic pleurisy............ & 1 \\
\hline Cholelithiasis.............. & 3 & 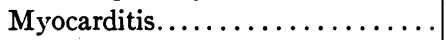 & 5 \\
\hline Hepatic cirrhosis.............. & 8 & Tuberculosis............... & 5 \\
\hline Convalescent from , catarrhal & & Angina pectoris.......... & 1 \\
\hline jaundice..$\ldots \ldots \ldots \ldots \ldots \ldots$ & 1 & Chronic endocarditis. ...... & 2 \\
\hline Chronic eczema $† \ldots \ldots \ldots \ldots \ldots$ & 11 & No disease; chronic............ & \\
\hline Pregnancy .............. & 1 & Outdoor visitor.......... & 1 \\
\hline Chronic nephritis..... & 8 & Chronic bronchitis............ & 1 \\
\hline Hemiplegia............. & 1 & 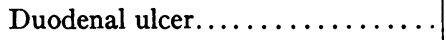 & 2 \\
\hline Encephalitis lethargica........ & 1 & 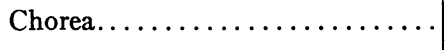 & 1 \\
\hline Total. & 99 & Total. & 29 \\
\hline
\end{tabular}

* All of these subjects came under observation because glycosuria was discovered during examination for life assurance policies. In fifteen of these there was a family history of diabetes.

$\dagger$ The Department of Dermatology is now making an investigation of this type of case. Some of these subjects have been noted to improve on low carbohydrate diets. In two of these there was a family history of diabetes.

(group 2) did there appear to be insufficient reason for the high blood sugar noted.

A detailed analysis of the maximum blood sugar concentrations following glucose ingestion are recorded in table 2. It is obvious from a glance at this table that the highest blood sugar values were found in group 1. Of the 29 cases in group. 2, 19 had blood sugars below 0.200 per cent. These results may be stated differently. Of 713 subjects 
only 29 showed hyperglycemias (blood sugars above 0.180 per cent) following ingestion of ordinary glucose that could not be attributed to disease. In 19 of these the blood sugars ranged between 0.181 and 0.200 per cent. Marked hyperglycemias (blood sugars above 0.200 per cent) were therefore found in only 10 out of 713 cases, an incidence

TABLE 2

Cases from table 1 analyzed with respect to maximum blood sugar concentration

\begin{tabular}{c|c|c}
\hline \multirow{2}{*}{ Maximum blood sugar } & \multicolumn{2}{|c}{ Incidence } \\
\cline { 2 - 3 } & Group 1 & Group 2 \\
\hline $0.181-0.185$ & cases & cases \\
$0.186-0.190$ & 11 & 8 \\
$0.191-0.195$ & 12 & 4 \\
$0.196-0.200$ & 4 & 5 \\
$0.201-0.205$ & 17 & 2 \\
$0.206-0.210$ & 6 & 3 \\
$0.221-0.215$ & 2 & 1 \\
$0.216-0.220$ & 3 & 0 \\
$0.221-0.225$ & 0 & 1 \\
$0.226-0.230$ & 16 & 0 \\
$0.231-0.235$ & 4 & 1 \\
$0.236-0.240$ & 10 & 1 \\
$0.241-0.245$ & 0 & 0 \\
$0.246-0.250$ & 3 & 0 \\
$0.251-0.255$ & 7 & 1 \\
$0.256-0.260$ & 0 & 0 \\
$0.261-0.265$ & 0 & 1 \\
$0.266-0.270$ & 0 & 0 \\
$0.271-0.275$ & 2 & 1 \\
$0.276-0.280$ & 0 & 0 \\
$0.281-0.285$ & 0 & 0 \\
$0.286-0.290$ & 0 & 0 \\
$0.291-0.295$ & 0 & 0 \\
$0.296-0.300$ & 1 & 0 \\
$0.301-$ & 1 & 0 \\
\hline
\end{tabular}

of 1.4 per cent. These data therefore appear to offer reasonable proof that in the great majority of instances, blood sugar values above 0.180 per cent are pathological. As to blood sugars above 0.200 per cent, the percentage incidence of these, in individuals with no apparent conditions to account for disturbance in carbohydrate metabolism, was so small that it would be practically necessary to assume an infallible technique to regard their occurrence as positive. 
Further evidence that maximum blood sugar concentrations above 0.180 per cent following ingestion of "ordinary" glucose are distinctly pathological was found by correlating post absorptive blood sugar values and blood sugar time curves. Of the 713 subjects, 103 had hyperglycemia (above 0.120 per cent) in the post absorptive state. These subjects were grouped according to their post absorptive blood sugars, 0.120 to 0.125 per cent, 0.126 to 0.130 per cent, etc. In table 3 are recorded in order the different groups, the number of individuals in each group, and the number of these who had diminished sugar tolerance. These results rather strikingly demonstrate the real significance of blood sugar time curves, in which maximum

TABLE 3

Correlation of high post-absorption blood sugar value with occurrence of diminished tolerance in blood sugar time curve

\begin{tabular}{c|c|c|c}
\hline \multirow{2}{*}{$\begin{array}{c}\text { Post absorptive blood } \\
\text { sugars }\end{array}$} & Number of cases & \multicolumn{2}{|c}{ Diminished tolerance } \\
\cline { 3 - 4 } & & Number of cases & Percentage incidence \\
\cline { 3 - 4 } per cent & 23 & & \\
$0.121-0.125$ & 23 & 14 & 60.8 \\
$0.126-0.130$ & 9 & 18 & 78.2 \\
$0.131-0.135$ & 14 & 8 & 88.8 \\
$0.136-0.140$ & 7 & 73 & 92.8 \\
$0.141-0.145$ & 6 & 6 & 100.0 \\
$0.146-0.150$ & 21 & 21 & 100.0 \\
$0.151-$ & & & 100.0 \\
\hline
\end{tabular}

sugar concentrations reach above 0.180 per cent. In no case with a basal blood sugar of 0.140 per cent or over, did the curves fail to rise above the 0.180 per cent level. In spite of the fact that the slight differences of values between 0.121 to 0.125 per cent may easily have been the results of technical errors, over sixty per cent of this group showed diminished tolerance in their curves. These results further corroborate the view expressed by Benedict that blood sugar values determined by the picric acid method have rarely misled the clinician in his interpretation.

An attempt was made to correlate glycosuria with the character of the blood sugar curve. Glycosuria was found in 309 out of the 713 cases an incidence of 43.3 per cent. This agrees very closely with that found by Gray in his study. As stated above, Gray found glycosuria in 129 out of 300 cases -an incidence of 43 per cent. Of our 268 
cases showing positive curves, 200 showed glycosuria. It will therefore be seen that 109 subjects with normal blood sugar curves had glycosuria. The deduction made from these observations is that glycosuria following ingestion of "ordinary" glucose is not a reliable clinical index of a disturbance of carbohydrate metabolism.

\section{SUMMARY}

A large number of blood sugar time curves were obtained in order to determine whether individuals, who have maximum blood sugar above 0.180 per cent, following ingestion of ordinary glucose, but whose blood sugar returns to the normal level at the end of three hours, may be regarded as normal.

By correlating the blood sugar time curves with the clinical pictures it was found, in the great majority of cases, that maximum concentrations above 0.180 per cent were associated with conditions known to cause or be associated with a disturbance of carbohydrate metabolism.

In view of these findings, it is regarded that the presence of a normal blood sugar three hours after glucose ingestion is not a sufficient basis for the diagnosis of a normal carbohydrate metabolism.

A blood sugar increase of over 0.180 under the same set of conditions, should, in the majority of cases, be regarded as pathological. This figure becomes more significant in view of the fact that the prevalent method of determining blood sugar (Folin and $\mathrm{Wu}$ ), yields, as a rule, values lower than the picric acid method. ${ }^{3}$

This work was done with the technical assistance of Miss Althea B. Frith, Miss Jane Spier and Miss Helen McGachen.

\section{BIBLIOGRAPHY}

1. Gray, H.: Arch. Int. Med., 1923, xxxi, 241. Blood Sugar Standards.

2. Benedict, S. R.: Jour. Biol: Chem., 1925, lxiv, 207. The Determination of Blood Sugar.

\footnotetext{
${ }^{3}$ While this paper was in the press an article by Petty \& Stoner appeared in the American Journal of Medical Sciences (1926, clxxi, 42), on "Respiratory quotient curves in the diagnosis of diabetes." By respiratory metabolism data these workers came to the same conclusion as we have, namely, that a number of individuals whose blood sugar was normal before and three hours after the administration of glucose were shown to be definitely diabetic, and that such blood sugar findings do not form a sufficient basis for the exclusion of the diagnosis of diabetes.
} 